\title{
Komunikasi Terapeutik Perawat Berhubungan dengan Tingkat Kecemasan Pasien Pre-Operasi di Ruang Instalasi Bedah Sentral RSUD Saras Husada Purworejo
}

\author{
Warsini $^{1}$, Winda Irwanti $^{2}$, R. Agus Siswanto ${ }^{3}$ \\ 1,2 Sekolah Tinggi Ilmu Kesehatan Alma Ata Yogyakarta \\ Jalan Ringroad Barat Daya No 1 Tamantirto, Kasihan, Bantul, Yogyakarta \\ ${ }^{3}$ RSUD Saras Husada Purworejo Jalan Jenderal Sudirman No. 60 Purworejo Jawa Tengah
}

\begin{abstract}
Abstrak
Gejala kecemasan yang berhubungan dengan kondisi medis umum sering ditemukan, walaupun insidensi bervariasi untuk masing-masing kondisi tersebut. Tindakan pembedahan merupakan ancaman potensial yang mengancam danmembangkitkan reaksi stres fisiologis maupun psikologis. Salah satu faktor yang dapat menurunkan tingkat kecemasan pasien yaitu dengan komunikasi terapeutik perawat. Tujuan penelitian untuk mengetahui hubungan komunikasi terapeutik dengan tingkat kecemasan pada pasien pre-operasi di ruang Instalasi Bedah Sentral (IBS) RSUD Saras Husada Purworejo. Jenis peneltian ini adalah observasional dengan pendekatan cross sectional. Populasi dalam penelitian ini adalah pasien pre-operasi di ruang IBS RSUD Saras Husada Purworejo. Teknik pengambilan sampel yaitu accidental sampling. Jumlah sampel dalam peneltian ini adalah 81 orang. Analisis data menggunakan kendall tau. Hasil penelitian didapatkan bahwa komunikasi terapeutik perawat tergolong cukup baik yaitu sebesar 37,0\%. Tingkat kecemasan pasien pre-operasi sebagian besar mengalami kecemasan sedang yaitu sebesar 44,4\%. Hasil uji statistik dengan menggunakan Kendal tau diperoleh nilai $p=0,000(p<0,05)$. Ada hubungan komunikasi terapeutik perawat dengan tingkat kecemasan pasien pre-operasi. Kesimpulan terdapat hubungan komunikasi terapeutik dengan tingkat kecemasan pada pasien pre-operasi di ruang IBS RSUD Saras Husada Purworejo.
\end{abstract}

Kata Kunci: komunikasi terapeutik, kecemasan, pre-operasi

\section{Nursing Therapeutic Communication Had Relationship with Anxiety Level of Preoperative Patients in Central Surgical Instalation Room at RSUD Saras Husada Purworejo}

\begin{abstract}
The symptoms of anxiety relate to medical condition are often found, though there are various incidences for each condition. The surgery is a potential threat that may rise stress reaction either physically or psychologically. One factor that may decrease the level of anxiety of patients is nursing therpeutic communication. The purposes of this study were to know the relationship between nursing therapeutic communication and anxiety level of preoperative patients in central surgical instalation room at RSUD Saras Husada Purworejo. This study was used an observational with a cross sectional design. The population in this study was preoperative patients in central surgical instalation room at RSUD Saras Husada Purworejo. Samples were obtained by accidental sampling technique, which consisted of 81 respondent. Data analysis was done by Kendal Tau test. The results showed that nursing therapeutic communication was $37.0 \%$ in a good category. Anxiety level of preoperative patients was $44.4 \%$ in average level. The result of Kendall Tau test showed a $p$-value $=0.000(p<0.05)$. There was a relationship between nursing therapeutic communication and anxiety level of preoperative patients. In conclusion, there was a relationship between nursing therapeutic communication and anxiety level of preoperative patients in central surgical instalation room at RSUD Saras Husada Purworejo.
\end{abstract}

Keywords: therapeutic communication, anxiety, preoperative

Info Artikel:

Artikel dikirim pada 21 Mei 2015

Artikel diterima pada 23 Mei 2015 


\section{PENDAHULUAN}

Salah satu masalah gangguan emosional yang sering ditemui pada masyarakat dan menimbulkan dampak psikologis cukup serius adalah ansietas (kecemasan). Kecemasan adalah kekhawatiran yang tidak jelas dan menyebar berkaitan dengan perasaan tidak pasti dan tidak berdaya(1). Keadaan emosi ini tidak memiliki objek yang spesifik, dialami secara subjektif dan dikomunikasikan secara interpersonal. Kecemasan dapat disebabkan oleh adanya perasaan takut tidak diterima dalam lingkungan tertentu, pengalaman traumatis akan perpisahan atau kehilangan, rasa frustasi akibat kegagalan dalam mencapai tujuan dan ancaman terhadap integritas diri maupun konsep diri(2).

Salah satu contoh kecemasan yang sering dirasakan pasien adalah cemas pada saat menghadapi ancaman dan kejadian traumatik misalnya saat akan menjalani tindakan operasi terutama pasien yang pertama kali menjalani tindakan operasi. Tindakan pembedahan merupakan ancaman potensial maupun aktual pada integritas seseorang yang dapat membangkitkan reaksi stres fisiologis maupun psikologis, dan merupakan pengalaman yang sulit bagi hampir semua pasien. Maka tidak heran sering kali pasien dan keluarga menunjukkan sikap berlebihan dengan kecemasan yang dialami(3). Terjadinya gejala kecemasan yang berhubungan dengan kondisi medis umum sering ditemukan, walaupun insidensi gangguan variasi untuk masingmasing kondisi medis umum spesifik(4).

Salah satu faktor yang dapat menurunkan tingkat kecemasan pasien yaitu dengan memberikan komunikasi terapeutik kepada pasien pre-operasi. Hal ini berdasarkan teori yang diungkapkan Peplau, asuhan keperawatan yang berfokus pada individu, perawat dan proses interaktif yang menghasilkan hubungan antara perawat dan pasien(5). Berdasarkan teori ini pasien adalah individu dengan kebutuhan perasaan, dan keperawatan adalah proses interpersonal dan terapeutik, dimana perawat memiliki peran yang cukup penting dalam mempengaruhi, menurunkan kecemasan dan meningkatkan kesehatan pasien melalui proses komunikasi.

Komunikasi terapeutik adalah komunikasi yang direncanakan secara sadar, bertujuan dan kegiatan dipusatkan untuk mengatasi masalah yang dihadapi klien. Dengan komunikasi dan hubungan terapeutik perawat-klien diharapkan dapat menurunkan kecemasan klien. Klien merasa bahwa interaksinya dengan perawat merupakan kesempatan untuk berbagi pengetahuan, perasaan dan informasi dalam rangka mencapai tujuan keperawatan yang optimal, sehingga proses penyembuhan akan lebih cepat.
Potter dan Perry mengungkapkan bahwa komunikasi terapeutik termasuk komunikasi interpersonal dengan titik tolak saling memberikan pengertian antara perawat-klien dengan tujuan membantu klien memperjelas dan mengurangi beban pikiran serta diharapkan dapat menghilangkan kecemasan(5).

Berdasarkan hasil studi pendahuluan yang dilakukan pada tanggal 30 Mei 2013 di Ruang Instalasi Bedah Sentral RSUD Purworejo didapatkan jumlah pasien yang menjalani tindakan operasi sebanyak 420 orang pada bulan April-Mei 2013. Dari hasil wawancara kepada 8 orang pasien yang akan menjalani tindakan operasi, 5 orang mengalami kecemasan dan 3 orang tidak mengalami kecemasan. Pada pasien yang mengalami kecemasan tersebut mengungkapkan bahwa nyeri saat operasi, cemas menghadapi ruangan operasi dan peralatan pembedahan, takut keganasan penyakit (apabila diagnosis yang ditegakkan belum pasti), takut operasi gagal. Kurangnya komunikasi dari tenaga kesehatan khususnya perawat terutama dalam memberikan informasi tentang tindakan yang akan dilakukan (prosedur pembedahan) yang menyebabkan pasien kurang informasi. Kurangnya informasi yang diberikan oleh tenaga kesehatan menyebabkan pasien tidak mengetahui tentang tindakan yang dilakukan sehingga pasien merasa cemas.

Tujuan penelitian ini secara umum untuk mengetahui hubungan komunikasi terapeutik perawat dengan tingkat kecemasan pasien pre-operasi di ruang Instalasi Bedah Sentral RSUD Saras Husada Purworejo, secara khusus untuk mengetahui karakteristik responden, mengetahui karakteristik perawat, mengetahui komunikasi terapeutik perawat, mengetahui tingkat kecemasan pasien pre-operasi, dan untuk menganalisis hubungan komunikasi terapeutik perawat dengan tingkat kecemasan pasien pre-operasi di ruang Instalasi Bedah Sentral RSUD Saras Husada Purworejo.

\section{BAHAN DAN METODE}

Jenis penelitian ini merupakan penelitian observasional dengan penelitian cross sectional. Penelitian dilakukan di Instalasi Bedah Sentral RSUD Saras Husada Purworejo pada bulan Agustus sampai September 2013. Populasi pada penelitian ini adalah seluruh pasien di Instalasi Bedah Sentral yang dilakukan operasi di RSUD Saras Husada Purworejo berdasarkan jumlah pasien pada bulan April sampai Mei 2013 sebanyak 420 orang. Jumlah sampel 81 orang dengan teknik pengambilan sampel menggunakan accidental sampling, dengan kriteria inklusi: Pasien pre operasi di Instalasi Bedah 
Sentral, operasi ringan sampai dengan berat, pasien berusia 15-65 tahun, pasien yang operasi pertama kali, bersedia menjadi responden. Kriteria ekslusi: Pasien dengan operasi cyto. Alat yang digunakan untuk mengumpulkan data pada penelitian ini adalah kuesioner untuk mengukur komunikasi terapeutik perawat. Kuesioner telah dilakukan uji validitas dan reliabilitas. Hasil uji validitas didapat rentang nilai $r$ hasil $0,523-0,984$, maka $r_{\text {hasii }}>r_{\text {tabel }}(0,444)$. Uji reliabilitas di dapatkan hasil sebesar $0,7536^{6}$. Tingkat kecemasan pasien pre- operasi diukur dengan analog anxiety scale (AAS) yang merupakan modifikasi dari halminton rating scale for anxiety(7), yang telah diuji validitas dan reliabilitasnya didapatkan korelasi ( $r=0,57-0,84)$ yang menyatakan AAS cukup valid dan reliabel untuk digunakan sebagai instrumen.

\section{HASIL DAN BAHASAN}

\section{Karakteristik Responden}

Distribusi frekuensi karakteristik responden di instalasi bedah sentral RSUD Saras Husada Purworejo 2013 dibagi atas jenis kelamin, umur, dan jenis pembedahan.

Tabel 1. Distribusi Frekuensi Karakteristik Responden di Instalasi Bedah Sentral RSUD Saras Husada Purworejo 2013

\begin{tabular}{lcc}
\hline \multicolumn{1}{c}{ Karakteristik } & f & $\%$ \\
\hline $\begin{array}{l}\text { Jenis Kelamin } \\
\text { Laki-Laki }\end{array}$ & 35 & 43,2 \\
$\quad$ Perempuan & 46 & 56,8 \\
Umur & & \\
$\quad$ 15-64 Tahun (usia & 63 & 77,8 \\
$\quad$ produktif) & & \\
$\quad$ >64 Tahun (tidak & 18 & 22,2 \\
$\quad$ produktif) & & \\
Jenis Pembedahan & & \\
$\quad$ Sedang & 58 & 71,6 \\
$\quad$ Berat & 23 & 28,4 \\
Total & 81 & 100,0 \\
\hline
\end{tabular}

Sumber: Data Primer Tahun 2013

Berdasarkan Tabel 1 frekuensi karakteristik responden, dimana paling banyak jenis kelamin perempuan $46(56,8 \%)$, terbanyak berumur antara 1564 tahun sebanyak $63(77,8 \%)$ dan jenis pembedahan yaitu sedang sebanyak 58 (71,6\%).

Berdasarkan Tabel 2 frekuensi karakteristik perawat, dimana paling banyak jenis kelamin perempuan yaitu 13 orang $(68,4 \%)$ dengan pendidikan DIII Keperawatan yaitu 9 orang $(47,4 \%)$.

Menurut Potter dan Perry salah satu faktor yang mempengaruhi komunikasi yaitu gender (jenis kelamin)(5). Perbedaan jenis kelamin mempengaruhi
Tabel 2. Distribusi Frekuensi Karakteristik Perawat di Instalasi Bedah Sentral RSUD Saras Husada Purworejo 2013

\begin{tabular}{lcc}
\hline Karakteristik & $\mathbf{f}$ & \% \\
\hline Jenis Kelamin & 6 & 31,6 \\
Laki-Laki & 13 & 68,4 \\
Perempuan & & \\
Tingkat Pendidikan & 3 & 15,8 \\
SPK & 9 & 47,4 \\
DIII Keperawatan & 7 & 36,8 \\
S1 Keperawatan & 19 & 100,0 \\
Total & &
\end{tabular}

Sumber: Data Primer Tahun 2013

proses komunikasi. Pria dan wanita memiliki gaya komunikasi yang berbeda dan satu sama lain saling mempengaruhi proses komunikasi secara unik. Wanita lebih halus di bandingkan dengan pria, sehingga mempermudah dalam komunikasi.

Menurut Potter dan Perry komunikasi dapat menjadi sulit ketika orang yang berkomunikasi memiliki tingkat pengetahuan yang berbeda. Pesan akan menjadi tidak jelas jika kata-kata dan ungkapan yang digunakan tidak dikenal oleh pendengar(5).

\section{Komunikasi Terapeutik Perawat di Istalasi Bedah Sentral RSUD Saras Husada Purworejo}

Distribusi frekuensi kategori komunikasi terapeutik perawat di instalasi bedah sentral RSUD Saras Husada Purworejo 2013 dibagi atas 3 kategori, yaitu: baik, cukup baik, dan kurang baik.

Tabel 3. Distribusi Frekuensi Kategori Komunikasi Terapeutik Perawat di Instalasi Bedah Sentral RSUD Saras Husada Purworejo 2013

\begin{tabular}{lcc}
\hline $\begin{array}{c}\text { Kategori Komunikasi } \\
\text { Terapeutik }\end{array}$ & $\mathbf{f}$ & $\%$ \\
\hline Baik & 22 & 27,2 \\
Cukup baik & 30 & 37,0 \\
Kurang baik & 29 & 35,8 \\
Total & 81 & 100,0 \\
\hline
\end{tabular}

Sumber: Data Primer Tahun 2013

Berdasarkan Tabel 3 dimana sebagian besar komunikasi terapeutik perawat tergolong cukup baik yaitu sebesar 30 orang $(37,0 \%)$. Hal ini sesuai dengan penelitian yang dilakukan Puyan, dimana komunikasi terapeutik tergolong cukup sebesar 51,5\%(8).

\section{Kecemasan Responden di Instalasi Bedah Sentral RSUD Saras Husada Purworejo}

Distribusi frekuensi tingkat kecemasan responden di instalasi bedah sentral RSUD Saras 
Husada Purworejo 2013 dibagi atas 4 tingkatan, yaitu ringan, sedang, berat, dan panik.

Tabel 4. Distribusi Frekuensi Tingkat Kecemasan Responden di Instalasi Bedah Sentral RSUD Saras Husada Purworejo 2013

\begin{tabular}{lcc}
\hline $\begin{array}{c}\text { Tingkat } \\
\text { Kecemasan }\end{array}$ & $\mathbf{f}$ & \% \\
\hline Ringan & 26 & 32,1 \\
Sedang & 36 & 44,4 \\
Berat & 11 & 13,6 \\
Panik & 8 & 9,9 \\
Total & 81 & 100,0 \\
\hline
\end{tabular}

Sumber: Data Primer Tahun 2013

Berdasarkan Tabel 4 menunjukkan sebagian besar responden mengalami tingkat kecemasan tergolong sedang yaitu sebesar 36 orang $(44,4 \%)$. Penelitian Mulyani, dkk menunjukkan bahwa paisen pra bedah mayor sebagian besar mengalami kecemasan(9).

\section{Hubungan Jenis Kelamin dengan Kecemasan}

Hasil tabulasi silang antara jenis kelamin dengan tingkat kecemasan pasien pre operasi ditunjukkan pada Tabel 5.

Responden yang berjenis kelamin perempuan lebih banyak menderita kecemasan ringan, yaitu 22 $(27,2 \%)$ orang sedangkan responden laki-laki lebih banyak tingkat kecemasan sedang, yaitu 14 (17,3\%) orang. Sedangkan tingkat kecemasan tergolong panik dengan jenis kelamin perempuan sebanyak $8(9,9 \%)$ orang lebih besar dari jenis kelamin laki-laki sebanyak 0 (tidak ada laki-laki yang mengalami kecemasan dengan kategori panik).

Penelitian ini sesuai dengan penelitian yang dilakukan Mariyam dan Kurniawan bahwa sebagian besar besar responden dan mengalami kecemasan adalah perempuan(10). Hasil ini juga sesuai dengan penelitian Ainun, dimana jenis kelamin pasien pre-operasai apendictomy sebagian besar adalah perempuan yaitu sebesar $57 \%(11)$. Menurut Gunarso, 1995 dalam Mariyam dan
Kurniawan, mengatakan bahwa perempuan lebih cenderung mengalami kecemasan dibandingkan dengan laki-laki(10). Perempuan dirasa lebih sensitif terhadap permasalahan, sehingga mekanisme koping perempuan lebih kurang baik dibandingkan laki-laki.

Berdasarkan Tabel 5 menunjukkan tabulasi silang antara jenis kelamin dengan tingkat kecemasan pasien pre-operasi didapatkan jenis kelamin laki-laki sebanyak $35(43,2 \%)$ orang sebagian besar mengalami kecemasan ringan sebanyak $20(24,7 \%)$ orang dan tidak ada yang mengalami panik. Sedangkan jenis kelamin perempuan sebanyak $46(56,8 \%)$ orang sebagian besar mengalami kecemasan sedang yaitu sebanyak $22(27,2 \%)$ orang dan paling sedikit mengalami kecemasan ringan yaitu sebanyak 6 $(7,4 \%)$ orang.

Berdasarkan hasil uji statistik dengan menggunakan kendall tau didapatkan nilai $p$-value $=0,000$ dengan nilai $r=0,503$ yang artinya terdapat hubungan dengan kekuatan hubungan sedang antara jenis kelamin dengan tingkat kecemasan pada pasien pre-operasi di instalasi bedah sentral RSUD Saras Husada Purworejo.

\section{Hubungan antara Umur dengan Kecemasan}

Frekuensi responden yang akan menjalani pembedahan sebagian besar tergolong usia produktif yaitu 15-64 tahun sebanyak 63 orang atau sebesar $77,8 \%$.

Hasil tabulasi silang antara umur dengan tingkat kecemasan pasien pre-operasi ditunjukkan pada Tabel 6 usia 15-64 tahun sebanyak 34 (42,0\%) orang lebih besar dari usia $>64$ tahun sebanyak 2 $(2,5 \%)$ orang dengan kecemasan sedang. Sedangkan kategori panik, dimana usia 15-64 tahun sebanyak $7(8,6 \%)$ orang lebih besar dari usia $>64$ tahun sebanyak $1(1,2 \%)$ orang.

Berdasarkan hasil uji statistik dengan kendall tau didapatkan nilai $p$-value $=0,000$ dengan nilai $r=0,467$ yang artinya terdapat hubungan dengan kekuatan hubungan sedang antara umur dengan tingkat kecemasan. Hal ini sesuai dengan penelitian yang dilakukan Mariyam dan Kurniawan mengatakan

Tabel 5. Hubungan antara Jenis Kelamin dengan Tingkat Kecemasan Pasien Pre Operasi di Instalasi Bedah Sentral RSUD Saras Husada Purworejo 2013

\begin{tabular}{|c|c|c|c|c|c|c|c|c|c|c|c|c|}
\hline \multirow{3}{*}{$\begin{array}{c}\text { Jenis } \\
\text { Kelamin }\end{array}$} & \multicolumn{10}{|c|}{ Tingkat Kecemasan } & \multirow{3}{*}{$p$-value } & \multirow{3}{*}{$\mathbf{r}$} \\
\hline & \multicolumn{2}{|c|}{ Ringan } & \multicolumn{2}{|c|}{ Sedang } & \multicolumn{2}{|c|}{ Berat } & \multicolumn{2}{|c|}{ Panik } & \multicolumn{2}{|c|}{ Total } & & \\
\hline & $\mathbf{n}$ & $\%$ & $\mathbf{n}$ & $\%$ & $\mathbf{n}$ & $\%$ & $\mathbf{n}$ & $\%$ & $\mathbf{n}$ & $\%$ & & \\
\hline Laki-Laki & 20 & 24,7 & 14 & 17,3 & 1 & 1,2 & 0 & 0,0 & 35 & 43,2 & 0000 & 0.503 \\
\hline Perempuan & 6 & 7,4 & 22 & 27,2 & 10 & 12,3 & 8 & 9,9 & 46 & 56,8 & 0,000 & \\
\hline Total & 26 & 32,1 & 36 & 44,4 & 11 & 13,6 & 8 & 9,9 & 81 & 100,0 & & \\
\hline
\end{tabular}

Sumber: Data Primer Tahun 2013 
bahwa usia muda lebih mudah mengalami cemas daripada usia tua(10). Penduduk muda di bawah 15 tahun umumnya dianggap sebagai penduduk yang belum produktif karena secara ekonomis masih tergantung pada orang tua atau orang lain yang menanggungnya. Selain itu penduduk berusia di atas 65 tahun juga dianggap tidak produktif lagi sesudah melewati masa pensiun.

\section{Hubungan antara Pembedahan dengan Kecemasan}

Hasil tabulasi silang antara jenis pembedahan dengan tingkat kecemasan pasien pre operasi ditunjukkan pada Tabel 7.

Berdasarkan Tabel 7 dapat dilihat bahwa jenis pembedahan sedang sebanyak $29(35,8 \%)$ orang lebih besar dari jenis pembedahan kategori berat sebanyak $7(8,6 \%)$ orang dengan tingkat kecemasan sedang. Sedangkan tingkat kecemasan kategori panik dengan jenis pembedahan sedang sebanyak $1(1,2 \%)$ orang lebih kecil dari jenis pembedahan kategori berat sebanyak $7(8,6 \%)$ orang. Berdasarkan hasil uji statistik dengan kendall tau didapatkan nilai $p$-value $=0,005$ dengan nilai $r=0,292$, yang artinya terdapat hubungan dengan kekuatan hubungan rendah antara jenis pembedahan dengan tingkat kecemasan.

\section{Hubungan Kategori Komunikasi Terapeutik dengan Tingkat Kecemasan Pasien Pre-Operasi di Ruang IBS RSUD Saras Husada Purworejo}

Hasil tabulasi silang antara komunikasi terapeutik dengan kecemasan pasien pre-operasi dapat dilihat pada Tabel 8.

Berdasarkan Tabel 8 didapatkan bahwa tingkat kecemasan ringan-sedang dengan komunikasi terapeutik kategori baik sebanyak $19(23,5 \%)$ orang, cukup $28(34,6 \%)$ orang dan kurang sebanyak 15 $(18,5 \%)$ orang, sedangkan tingkat kecemasan kategori berat dan panik dengan komunikasi tergolong baik sebanyak $3(3,7 \%)$ orang, cukup sebanyak $2(2,4 \%)$ orang dan kurang sebanyak $14(17,3 \%)$ orang.

Hubungan komunikasi terapeutik perawat dengan tingkat kecemasan pasien pre-operasi didapatkan hasil uji statistik dengan menggunakan kendall tau $r=0,336$ diperoleh nilai $p$-value $=0,000$

Tabel 6. Hubungan Umur dengan Tingkat Kecemasan Pasien Pre Operasi di Instalasi Bedah Sentral RSUD Saras Husada Purworejo 2013

\begin{tabular}{|c|c|c|c|c|c|c|c|c|c|c|c|c|}
\hline \multirow{3}{*}{ Umur } & \multicolumn{10}{|c|}{ Tingkat Kecemasan } & \multirow{3}{*}{$p$-value } & \multirow{3}{*}{$\mathbf{r}$} \\
\hline & \multicolumn{2}{|c|}{ Ringan } & \multicolumn{2}{|c|}{ Sedang } & \multicolumn{2}{|c|}{ Berat } & \multicolumn{2}{|c|}{ Panik } & \multicolumn{2}{|c|}{ Total } & & \\
\hline & $\mathbf{n}$ & $\%$ & $\mathbf{n}$ & $\%$ & $\mathbf{n}$ & $\%$ & $\mathbf{n}$ & $\%$ & $\mathbf{n}$ & $\%$ & & \\
\hline 15-64 Tahun & 11 & 13,6 & 34 & 42,0 & 11 & 1,6 & 7 & 8,6 & 63 & 77,8 & \multirow{3}{*}{0,000} & \multirow{3}{*}{0,467} \\
\hline$>64$ Tahun & 15 & 18,5 & 2 & 2,5 & 0 & 0,0 & 1 & 1,2 & 18 & 22,2 & & \\
\hline Total & 26 & 32,1 & 36 & 44,4 & 11 & 13,6 & 8 & 9,9 & 81 & 100,0 & & \\
\hline
\end{tabular}

Sumber: Data Primer Tahun 2013

Tabel 7. Hubungan Jenis Pembedahan dengan Tingkat Kecemasan Pasien Pre Operasi di instalasai Bedah Sentral RSUD Saras Husada Purworejo 2013

\begin{tabular}{|c|c|c|c|c|c|c|c|c|c|c|c|c|}
\hline \multirow{3}{*}{$\begin{array}{c}\text { Jenis } \\
\text { Pembedahan }\end{array}$} & \multicolumn{10}{|c|}{ Tingkat Kecemasan } & \multirow{3}{*}{ p-value } & \multirow{3}{*}{$\mathbf{r}$} \\
\hline & \multicolumn{2}{|c|}{ Ringan } & \multicolumn{2}{|c|}{ Sedang } & \multicolumn{2}{|c|}{ Berat } & \multicolumn{2}{|c|}{ Panik } & \multicolumn{2}{|c|}{ Total } & & \\
\hline & $\mathrm{n}$ & $\%$ & $\mathbf{n}$ & $\%$ & $\mathbf{n}$ & $\%$ & $\mathbf{n}$ & $\%$ & $\mathbf{n}$ & $\%$ & & \\
\hline Sedang & 21 & 25,9 & 29 & 35,8 & 7 & 8,6 & 1 & 1,2 & 58 & 71,6 & & \\
\hline Berat & 5 & 6,2 & 7 & 8,6 & 4 & 4,9 & 7 & 8,6 & 23 & 28,4 & 3 & 292 \\
\hline Total & 26 & 32,1 & 36 & 44,4 & 11 & 13,6 & 8 & 9,9 & 81 & 100,0 & & \\
\hline
\end{tabular}

Sumber: Data Primer Tahun 2013

Tabel 8. Hubungan Kategori Komunikasi Terapeutik dengan Tingkat Kecemasan Pasien Pre-Operasi di Ruang IBS RSUD Saras Husada Purworejo 2013

\begin{tabular}{|c|c|c|c|c|c|c|c|c|}
\hline \multirow{3}{*}{$\begin{array}{l}\text { Kategori Komunikasi } \\
\text { Terapeutik }\end{array}$} & \multicolumn{4}{|c|}{ Tingkat Kecemasan } & \multirow{2}{*}{\multicolumn{2}{|c|}{ Total }} & \multirow{3}{*}{$\mathbf{r}$} & \multirow{3}{*}{ p-value } \\
\hline & \multicolumn{2}{|c|}{ Ringan-Sedang } & \multicolumn{2}{|c|}{ Berat-Panik } & & & & \\
\hline & $\mathbf{n}$ & $\%$ & $\mathbf{n}$ & $\%$ & $\mathbf{n}$ & $\%$ & & \\
\hline Baik & 19 & 23,5 & 3 & 3,7 & 22 & 27,2 & & \\
\hline Cukup & 28 & 34,6 & 2 & 2,4 & 30 & 37,0 & 0,336 & 0,001 \\
\hline Kurang & 15 & 18,5 & 14 & 17,3 & 29 & 35,8 & & \\
\hline Total & 62 & 76,5 & 19 & 23,5 & 81 & 100,0 & & \\
\hline
\end{tabular}

Sumber: Data Primer Tahun 2013 
$(p<0,05)$ yang artinya bahwa terdapat hubungan dengan kekuatan hubungan rendah antara komunikasi terapeutik dengan tingkat kecemasan pada pasien pre-operasi dengan hubungan korelasi rendah.

Hasil penelitian ini sesuai dengan penelitian Ainun, menunjukkan bahwa terdapat hubungan antara dukungan keluarga dengan tingkat kecemasan pasien pre-operasi apendictomy di ruang Flamboyan RSUD Tarakan Pemerintah Provinsi Kalimantan Timur, dimana didapatkan nilai $p$-value $=0,01$. Ainun dalam penelitiannya mengatakan bahwa untuk mengurangi kecemasan pada pasiennya dengan memberikan adalah dukungan informasional, dukungan jasmani maupun rohani(11). Hasil penelitian ini didukung juga oleh penelitian Mulyani, dkk yang menunjukkan bahwa komunikasi terapeutik perawat-klien memiliki hubungan bermakna dengan kecemasan klien pra bedah mayor didapatkan nilai $p$-value $=0,000(p<0,05)(9)$.

Hasil penelitian ini juga sesuai dengan penelitian Sawitri dan Sudaryanto yang berjudul pengaruh pemberian informasi pra bedah terhadap tingkat kecemasan pada pasien pra bedah mayor di bangsal orthopedi RSUI Kustati Surakarta. Hasil penelitian ini di dapatkan nilai $p$-value $=0,000(p<0,05)$ yang menunjukkan bahwa terdapat hubungan antara pemberian informasi pra bedah terhadap tingkat kecemasan pasien pra bedah mayor di bangsal ortopedi RSUI Kustati Surakarta(12).

Beberapa faktor-faktor yang mempengaruhi tingkat kecemasan pasien pre-operasi yaitu menyangkut nyeri setelah pembedahan, takut terjadi perubahan fisik (menjadi buruk rupa dan tidak berfungsi normal), takut keganasan (bila diagnosa yang ditegakkan belum pasti), takut dan cemas mengalami kondisi yang sama, takut berada di ruang operasi, peralatan bedah dan petugas, takut mati saat dilakukan anastesi, dan takut operasi akan gagal(5). Selain faktor itu faktor lain yang dapat mempengaruhi kecemasan yaitu jenis kelamin, usia, dan jenis pembedahan. Jenis kelamin sangat berpengaruh terhadap kecemasan, dimana yang paling mudah mengalami kecemsan adalah wanita. Menurut Wibisono kecemasan dapat terjadi pada semua usia, lebih sering terjadi pada usia dewasa dan lebih banyak pada wanita(13). Menurut Hawari umumnya yang mengalami kecemasan lebih banyak adalah umur 18-54 tahun(14).

Salah satu faktor yang dapat menurunkan tingkat kecemasan pasien yaitu dengan memberikan komunikasi terapeutik kepada pasien pre-operasi. Hal ini berdasarkan teori yang diungkapkan Peplau dalam Potter dan Perry berfokus pada individu, perawat dan proses interaktif yang menghasilkan hubungan antara perawat dan pasien. Berdasarkan teori ini pasien adalah individu dengan kebutuhan perasaan, dan keperawatan adalah proses interpersonal dan terapeutik, dimana perawat memiliki peran yang cukup penting dalam mempengaruhi, menurunkan kecemasan dan meningkatkan kesehatan pasien melalui proses komunikasi. Faktor-faktor yang mempengaruhi komunikasi yaitu gender (jenis kelamin). Perbedaan jenis kelamin mempengaruhi proses komunikasi. Pria dan wanita memiliki gaya komunikasi yang berbeda dan satu sama lain saling mempengaruhi proses komunikasi secara unik(5).

Tingkat hubungan antara komunikasi dengan tingkat kecemasan tergolong rendah (tidak kuat) dengan nilai $r=0,336$. Sesuai dengan pendapat Sugiyono mengatakan bahwa rentang 0,200-0,399 tingkat hubungan tergolong rendah(15). Faktor lain yang mempengaruhi komunikasi yaitu pendidikan, pendidikan berpengaruh terhadap pola pikir individu. Pendidikan yang tinggi akan memiliki pengetahuan dan pola pikir tinggi. Menurut Potter dan Perry komunikasi dapat menjadi sulit ketika orang yang berkomunikasi memiliki tingkat pengetahuan yang berbeda. Pesan akan menjadi tidak jelas jika kata-kata dan ungkapan yang digunakan tidak dikenal oleh pendengar(5). Oleh karena itu, pendidikan yang tinggi akan memiliki pengetahuan yang baik sehingga akan memudahkan dalam berkomunikasi dengan pasien, terutama komunikasi terapeutik sehingga kecemasan pasien komunikasi terapeutik perawat kepada pasien dapat menurunkan tingkat kecemasan pada pasien yang akan melakukan tindakan pembedahan terjadi penurunan.

\section{SIMPULAN DAN SARAN}

Berdasarkan hasil penelitian dan uji statistik dengan menggunakan kendall tau dapat disimpulkan bahwa karakteristik responden terbanyak perempuan, usia terbanyak antara 15-64, jenis pembedahan sebagian besar sedang. Karakteristik perawat sebagian besar jenis kelamin perempuan dan tingkat pendidikan sebagian besar DIII keperawatan. Komunikasi terapeutik perawat sebagian besar tergolong cukup. Tingkat kecemasan pasien preoperasi sebagian besar mengalami kecemasan sedang. Terdapat hubungan komunikasi terapeutik dengan tingkat kecemasan pasien pre-operasi di ruang IBS RSUD Saras Husada Purworejo, dimana dari hasil uji statistik dengan menggunakan kendal tau diperoleh nilai $p$-value $=0,000(p<0,05)$.

Saran diharapkan bagi RSUD untuk meningkatkan pelayanan dengan Standar Operasional Prosedur (SOP) komunikasi terapeutik perawatpasien. Bagi tenaga keperawatan diharapkan meningkatkan pelayanan dalam hal mencegah 
atau mengurangi tingkat kecemasan pasien melalui komunikasi terapeutik.

\section{RUJUKAN}

1. Stuart, Laraia. Principle and Practice of Psychiatric Nursing. St Louis: Elsevier Mosby; 2005.

2. Suliswati. Analisis Faktor-Faktor Yang Berhubungan Dengan Tingkat Kecemasan Pada Pasien Pre Operasi di Ruang Kenanga BRSU Dr. H. Soewondo. Kendal; 2005.

3. Fitriya N. Teori Psikospiritual [internet]. 2009 [cited 2013 Jun 20]. Available from: http:// fikunpad. unpad. ac.id/?=192.

4. Ibrahim. Panik, Neurosis dan Gangguan Cemas. Tangerang: Jelajah Nusa; 2012.

5. Potter, Perry. Fundamental Keperawatan. Jakarta: EGC; 2005.

6. Maria. Hubungan Antara Pelaksanaan Komunikasi Terapeutik Perawat Dengan Tingkat Kepuasan Pasien di RSUD Dr. Soedjati Grobogan. Fakultas IImu Keperawatan Universitas Gajahmada; 2002.

7. Iskandar Y. Stres, Anexietas dan Penampilan. Jakarta: Yayasan Dharma Graha; 1984.

8. Puyan LH. Hubungan Komunikasi Terapeutik Perawat dengan Tingkat Kepuasan Pasien di
Puskesmas Dukun Magelang. Yogyakarta: PSIK STIKES Alma Ata; 2012.

9. Mulyani S, et al. Komunikasi dan Hubungan Terapeutik Perawat-Klien terhadap Kecemasan Pra-Bedah Mayor. Yogyakarta; 2008.

10. Mariyam, Kurniawan. Faktor-Faktor yang Berhubungan dengan Tingkat Kecemasan Orang Tua Terkait Hospitalisasi Anak Usia Toddler di RRSD RAA Soewonso Pati. J Keperawatan FIKKes; 2008.

11. Ainun J. Hubungan Antara Dukungan Keluarga dengan Tingkat Kecemasan pada Pasien Pre Operasi Appendictomy di ruang flamboyant RSUD Tarakan Pemerintah Provinsi Kalimantan Timur; 2012.

12. Sawitri E, Sudaryanto A. Pengaruh Pemberian Informasi Pra Bedah terhadap Tingkat Kecemasan pada Pasien Pra Bedah Mayor di Bangsal Orthopedi RSUI Kustati Surakarta. Surakarta: FIK UMS; 2004.

13. Wibisono S. Cemas: Konsep Diagnosis dan Prinsip Therapi. Jakarta: Majalah Dokter Keluarga. 1990;9.

14. Hawari D. Manajemen Stres Cemas dan Depresi. Jakarta: Fakultas Kedokteran Universitas Indonesia; 2004.

15. Sugiyono. Metode Penelitian Administrasi. Bandung: CV Alfabeta; 2007. 